\title{
Oral Submucous Fibrosis- A Review on Clinical Presentation, Histology, Epidemiology, Aetiology, Pathogenesis, Malignanat Potential and Management (Review Article)
}

\section{Authors \\ Dr Girish Aggarwal ${ }^{1}$, Dr Rajesh Bansal ${ }^{2}$, Dr Vandana Chabbra ${ }^{3}$, Dr Gourav Popli ${ }^{4}$ Dr Sangeet Sethi ${ }^{5}$, Dr Ankita Khatri ${ }^{6}$ \\ ${ }^{1}$ Senior Lecturer, Dept of Oral and Maxillofacial Surgery, Shaheed Kartar Singh Sarabha Dental College, Ludhiana \\ ${ }^{2}$ Professor and Head, Dept of Oral and Maxillofacial Surgery, Shaheed Kartar Singh Sarabha Dental College, Ludhiana}

${ }^{3}$ Reader, Dept of Oral and Maxillofacial Surgery, Shaheed Kartar Singh Sarabha Dental College, Ludhiana

${ }^{4}$ Senior Lecturer, Department of Oral and Maxillofacial Surgery, Subharti Dental College, Meerut

${ }^{5}$ Consultant Oral and Maxillofacial Surgery, New Delhi

${ }^{6}$ Postgraduate Student, Dept of Oral and Maxillofacial Surgery, M.M College of Dental Sciences, Ambala

Corresponding Author

\section{Dr Gourav Popli}

Senior Lecturer, Department of Oral and Maxillofacial Surgery, Subharti Dental College, Swami

Vivekanand Subharti University, Meerut

Email id:-drgp0250@gmail.com, Phone No:- +918475991147

\begin{abstract}
Oral submucous fibrosis (OSMF) is a chronic, devastating disease characterised by juxtaepithelial fibrosis of the oral cavity. ${ }^{(1)}$ Oral submucous fibrosis (OSMF) is a premalignant condition caused by betel chewing. It is very common in Southeast Asia but has started to spread to Europe and North America. OSMF can lead to squamous cell carcinoma, a risk that is further increased by concomitant tobacco consumption. OSMF is a diagnosis based on clinical symptoms and is confirmed by histopathology. Hypovascularity leading to blanching of the oral mucosa, staining of teeth and gingiva, and trismus are major symptoms. Major constituents of betel quid are arecoline from betel nuts and copper, which are responsible for fibroblast dysfunction and fibrosis. A variety of extracellular and intracellular signaling pathways might be involved $^{(2)}$. We review and discuss all OSMF, including the terminology, presentation, aetiology, and pathogenesis, and provide a brief overview of its conservative and surgical management.

KEYWORDS- Oral Submucous Fibrosis, Epidemiology, Aetiology, Pathogenesis, Clinical Presentation, Management.
\end{abstract}




\section{INTRODUCTION}

The most widely accepted definition of the disease by Pindborg and Sirsat is one of an insidious, chronic disease that affects any part of the oral cavity and sometimes the pharynx. Although occasionally preceded by, or associated with, formation of vesicles, it is always associated with a juxtaepithelial inflammatory reaction followed by fibroelastic change of the lamina propria and epithelial atrophy that leads to stiffness of the oral mucosa and causes trismus and an inability to eat. (3) A variety of etiologic factors including capsaicin, betel nut alkaloids, hypersensitivity, autoimmunity, genetic predisposition and chronic iron and vitamin B-complex deficiency have been suggested by various authors, the most common of which is chewing areca nut. Excessive use of areca nut may cause fibrosis due to increased synthesis of collagen and induce the production of free radicals and reactive oxygen species, which are responsible for high rate of oxidation / peroxidation of polyunsaturated fatty acids which affect essential constituents of cell membrane and might be involved in tumorigenesis. Arecanut chewing is deep rooted in Indian culture and has been used as a mouth freshening agent that has various symbolic roles throughout Indian history. The most alarming fact is that this habit is becoming increasingly popular among adolescents. $^{(4)}$

\section{CLINICAL PRESENTATION}

Clinical presentation depends on the stage of the disease. Initially, most patients present with a burning sensation or intolerance to spicy food, and they may have vesicles, particularly on the palate. Ulceration and dryness of the mouth is later followed by fibrosis of the oral mucosa, which leads to rigidity of the lips, tongue, and palate, and trismus. ${ }^{(5)}$ Pindborg in 1989 divided OSMF into 3 stages, on basis of clinical features ${ }^{(6)}$ :

Stage 1 (Stomatitis): It includes erythematous mucosa, vesicles, mucosal ulcers, melanotic mucosal pigmentation, and mucosal petechia.
Stage 2 (Fibrosis): fibrosis occurs in ruptured vesicles and ulcers when they heal, which is the hallmark of this stage. Early lesions demonstrate blanching of the oral mucosa. Older lesions include vertical and circular palpable fibrous bands in the buccal mucosa and around the mouth opening or lips, resulting in a mottled, marble like appearance of the mucosa because of the vertical, thick, fibrous bands running in a blanching mucosa. Specific findings include the following: (i) Reduction of the mouth opening (trismus) (ii) Stiff and small tongue; (iii) Blanched and leathery floor of the mouth; (iv) Fibrotic and depigmented gingiva; (v) Rubbery soft palate with decreased mobility; (vi) Blanched and atrophic tonsils; (vii) Shrunken budlike uvula; (viii) Sinking of the cheeks, not commensurate with age or nutritional status.

Stage 3 (Sequelae of OSMF): (i) Leukoplakia is precancerous and is found in more than $25 \%$ of individuals with OSMF. (ii) Speech and hearing deficits may occur because of involvement of the tongue and the Eustachian tubes. In addition to the above staging, in 1995 Khanna at al ${ }^{(7)}$ developed a group classification system for the surgical management of trismus. Group I: This is the earliest stage and is not associated with mouth opening limitations. It refers to patients with an interincisor distance of greater than $35 \mathrm{~mm}$. Group II: This refers to patients with an interincisor distance of 26-35 mm. Group III: These are moderately advanced cases. This stage refers to patients with an interincisor distance of 15-26 $\mathrm{mm}$. Fibrotic bands are visible at the soft palate, and pterygomandibular raphe and anterior tonsillar pillars. Group IVA: Trismus is severe, with an interincisor distance of less than $15 \mathrm{~mm}$ and extensive fibrosis of all the oral mucosa. Group IVB: Disease is most advanced, with premalignant and malignant changes throughout the mucosa. Early OSMF presents with a burning sensation in oral cavity aggravated by spicy food (42\%), followed by either hyper salivation or dryness of the mouth $(25 \%)$. ${ }^{(8)}$ It presents with blisters especially on the palate, ulcerations or 
recurrent generalized inflammation of the oral mucosa. Common initial symptoms are: Intolerance/Burning sensation in the mouth on consuming hot and spicy food: ${ }^{(9)}$

- Blanching, i.e., marble like appearance of the oral mucosa and stiffness of oral mucosa

- Reduced mobility of the soft palate and tongue

- Hypersalivation

- Defective gustatory sensation

- Dryness of the mouth

- Blisters on the palate, ulcerations or recurrent generalized inflammation of the oral mucosa

- Mild hearing loss due to blockade of Eustachian tube

- Trismus

In advanced OSMF, oral mucosa becomes blanched and slightly opaque with appearance of white fibrous bands on buccal mucosa, lips, soft palate, faucial pillars and tongue. With progressive fibrosis, stiffening of certain areas of mucosa occur which results in difficulty in opening of the mouth, difficulty in swallowing and inability to whistle or blow air. In severe cases, the patient cannot protrude the tongue beyond the incisor teeth and there is a progressive closure of the oral opening.

The oral mucosa is involved symmetrically and the fibrous bands in the buccal mucosa run in a vertical direction. The density of the fibrous deposit varies from a slight whitish area on the soft palate causing no symptoms to a dense fibrosis causing fixation and shortening or even deviation of the uvula and soft palate. Depending on the habit of chewing or swallowing tobacco, areca nuts and its related products, the fibrotic changes can be seen in the mucosa of the oral cavity or oesophagus. Laterality of OSMF depends on the fact that which side of the oral mucosa is more exposed to tobacco products. This is usually noted during examination that one side of the buccal mucosa is fibrosed whereas other side is completely normal
HISTOPATHOLOGICAL CLASSIFICATION OF OSMF ${ }^{(12)}$

Very early stage (Grade I):

- A finely fibrillar collagen, dispersed with marked edema.

- The fibroblastic response is strong.

- The blood vessels are sometimes normal, but more often they are dilated and congested.

- Inflammatory cells, mainly polymorphonuclear leukocytes with an occasional eosinophils are present.

\section{Early stage (Grade II):}

- The juxtaepithelial area shows early hyalinization.

- Plump young fibroblasts are present in moderate numbers.

- The blood vessels are dilated and congested.

- The inflammatory cells are mostly mononuclear lymphocytes, eosinophils and an occasional plasma cell.

\section{Moderately advanced stage (Grade III):}

- The collagen is moderately hyalinized.

- The fibroblastic response is less marked, the cells present being mostly adult fibrocytes.

- Blood vessels are normal or constricted.

- The inflammatory exudates consist of lymphocytes and plasma cells, although an occasional eosinophil is seen.

\section{Advanced stage (Grade IV):}

- The collagen is completely hyalinized.

- The hyalinized areas are devoid of fibroblasts.

- Blood vessels are completely obliterated or narrowed.

- The inflammatory cells are lymphocytes and plasma cells.

\section{EPIDEMIOLOGY ${ }^{(10,11)}$}

Geographically, OSMF has a specific distribution and affects predominantly Asians (and particularly Indians) from the southern states, and Taiwanese. 
Other series of OSMF in Europe, the Far East, and the Pacific Rim have been reported. An estimate from 1996 indicated that glob-ally, about 2.5 million people have OSMF, but studies have found that over 5 million people are affected in India alone ( $0.5 \%$ of the Indian population). It is also estimated that up to $20 \%$ of the world's population use betel nut in some form, so the incidence of OSMF is likely to be much higher than current estimates suggest, and it is regarded as a public health issue in the Indian subcontinent, the UK and South Africa. It is predominantly seen in the second or third decade, and recent data suggest a male predominance, however, both sexes are equally at risk. Oral cancer that arises in those who chew betel quid is one of the most common malignancies in south and southeast Asian countries.

\section{AETIOLOGY}

At first, OSMF was thought to be idiopathic, but it was later concluded to be multifactorial in origin, and possible aetiological factors include capsaicin in chillies, iron, zinc, and deficiencies in essential vitamins. ${ }^{(13)}$ Various auto antibodies and specific human leucocyte antigens in some patients have indicated an autoimmune role as well as a genetic predisposition for the disease. However, various epidemiological studies, large cross-sectional surveys, case control studies, and cohort and intervention studies have provided overwhelming evidence that areca-nut is the main aetiological factor in OSMF. The nut is the endosperm of the fruit of the Areca catechu palm tree. ${ }^{(7)} \mathrm{A}$ range of case-control studies have given convincing evidence that there is a definite dose-dependent relation between areca-nut and causation of the disease, and it is well known that the onset of the disease is directly proportional to the concentration, incidence, and duration of chewing the nut (without tobacco). Generally, younger patients develop clinical features of OSMF within 3.5 years from onset of the habit while in older patients it takes 6.5 years. ${ }^{(14)}$ Currently, in India, Pakistan, and Bangladesh, betel quid and gutkha are the most commonly used commercially freezedried areca-nut products. Gutkha (also spelled gutka or guthka), thought to be derived from Hindi meaning "a shred or small piece" is a light brown, grainy powder available incompact storable sachets. It consists mainly of areca-nut, tobacco, and flavours, and is typically taken to relieve stress. When chewed it dissolves quickly in saliva and provides central stimulation, which is said to be more intense than tobacco.

\section{PATHOGENESIS}

The relationship of OSMF to chewing of areca nut/quid or panmasala has been directly related to OSMF, whereas chewing or smoking tobacco did not increase the risk for OSMF. In a case-control study from Kerala, India, betel quid alone increased the odds ratio for OSMF to 56.2. ${ }^{(15)}$

\section{(1) Extracellular matrix and fibroblast changes:}

The most obvious changes occur in the extracellular matrix of the submucous tissue layer. Fibrosis is associated with quantitative and qualitative alterations of collagen deposition within the subepithelial layer of the oral mucosa. This is partly due to marked deficiencies in collagen and fibronectin phagocytosis by fibroblasts caused by betel nut alkaloids (arecoline, arecaidine). On the other hand, tannins from areca nuts increase collagen fiber resistance to collagenase. ${ }^{(14)}$

In vitro, areca nut extract suppresses the synthesis of 3-Hydroxy-proline and the growth and attachment to collagen of oral fibroblasts in a dose-dependent manner. Pretreatment of oral mucosa fibroblasts with other areca nut compounds such as buthionine sulfoximine or diethyl maleate potentiates the cytotoxic effects. (16) Over expression of stress protein colligin was found in $70 \%$ of OSMF patients. It has been suggested that colligin may contribute to the increased deposition of collagen I and thereby to fibrosis development in oral submucosa. ${ }^{(17)} \mathrm{CD} 34$ a marker of mucosal vascular endothelium and basic fibroblast growth factor are both increased 
in OSMF and demonstrate an association to the stage of fibrosis. ${ }^{(18)}$

\section{(2) Arecoline}

The major compound of areca nut can induce various growth factors like insulin-like growth factor-1 and keratinocyte growth factor-1, and basic protein cystatin $\mathrm{C}$, but inhibits proinflammatory cytokines like interleukin-6. Arecoline stimulates another key molecule in the regulation of fibrosis - the hypoxia-inducible factor- $1 \alpha-$ in a dose-dependent manner. ${ }^{(19)}$

\section{(3) Copper}

Copper is implicated in the pathogenesis of fibrotic disorders because it stimulates collagen synthesis in oral fibroblasts. Elevated serum copper levels are associated with duration of betel nut chewing and severity of OSMF.

\section{(4) Areca nuts}

It contains high copper concentrations compared to other nuts, and copper becomes liberated during chewing. Mass absorption spectrometry of buccal mucosa detected a mean tissue copper level of $5.5 \pm 2.9 \mu \mathrm{g} / \mathrm{g}$ in patients with OSMF compared with $4 \pm 1.9 \mu \mathrm{g} / \mathrm{g}$ in controls. Copper has been detected in the epithelium and the connective tissue of the OSMF specimens. Copper levels are significantly higher in commercial areca nut products compared with raw areca nut. ${ }^{(2)}$

\section{(5) Immune system}

Betel quid affects the immune system. The levels of transforming growth factor (TGF)- $\beta$ and interferon (IFN) $-\gamma$ are lower in mononuclear cells from OSMF patients than from controls. ${ }^{(2)}$

\section{(6) Antioxidant status and cytokines}

Glutathione S-transferases (GST) are part of the antioxidant system. GSTT1 and GSTM1 null phenotypes increase the risk of OSMF. Reduced glutathione levels in betel quid users are related to raised levels of the proinflammatory interleukin-6. Diminished levels of superoxide dismutase but increased levels of malondialdehyde - a lipid peroxidation product - have been detected in OSMF. ${ }^{(20)}$

\section{(7) The role of tobacco addition}

Several surveys show an increase in the incidence of OSMF when areca nut and tobacco consumption are combined. A relative risk of 489 has been reported for OSMF in consumers of areca nut/tobacco compared with nonusers. The consumers of mixed products are often younger. OSMF develops faster in these patients (after 2.7 years) than in betel quid chewers (after 8.6 years). Cancerous transformation appeared at an early age.

Both genotoxicity and carcinogenicity of areca nut and betel quid with or without tobacco admixture are well documented. Nitrosamines, reactive oxygen species, and depletion of endogenous antioxidant capacity are the dominant contributors. Oesophageal subepithelial fibrosis is seen more frequently in patients who had consumed areca nut and tobacco for longer than 5 years. ${ }^{(2)}$

\section{(8) Changes in gene expression and activity}

More recently, the expression profiles of genes in OSMF and normal oral mucosa have been studied more intensively. In one study, 14,500 genes were analyzed using gene chip arrays. The study demonstrated 716 genes were upregulated and 149 genes were downregulated in OSMF. The gene expression profiles of normal controls and OSMF patients were clearly distinct, in particular the genes involved in immune response, inflammatory response, and TGF- $\beta$-induced epithelialmesenchymal transition. ${ }^{(21)}$

In a comprehensive analysis of water-soluble and ethanol-soluble areca nut constituents, it was demonstrated that both alkaloid and polyphenol fractions induced TGF- $\beta$ signaling in human keratinocytes. Involved genes included $T G F-\beta 2$, $S M A D-3$, matrix metalloproteinase (MMP)1, MMP2, and MMP9, and others. In contrast, no TGF signaling was induced in fibroblasts. ${ }^{(22)}$

\section{RELATED CONDITIONS IN ORAL SUBMUCOUS FIBROSIS}

Oral leukoplakia and OSMF are clinically distinct premalignant states that precede the development of oral Squamous Cell Carcinoma (SCC). Oral 
leukoplakia is an early sign of mucosal damage. It can appear as macular, plaque-like, erosive, or verrucous lesion with a homogeneous or speckled white appearance. Erythroplakia would be the reddish counterpart that poses a greater risk for malignant transformation into invasive SCC. In more-advanced OSMF, fibrosis is a hallmark leading to impairment in mouth opening, speaking and swallowing.

Oral cancer accounts for up to $40 \%$ of all malignancies in Asia. Tobacco smoking and chewing betel quid containing tobacco are the major risk factors for oral cancer, whereas betel quid without tobacco significantly increased oral cancer risk in only one study.

Attempts have been made to identify specific molecular events as prognostic markers to identify oral precancerous lesions with higher malignant potential. The expression of TGF- $\alpha$ and epidermal growth factor-receptor was upregulated in oral leukoplakia, OSMF, and oral SCC relative to normal oral mucosa.

Arecoline is considered the most important etiological factor, but addition of peroxynitrite (a reaction product of cigarette smoking) and nicotine acted as a synergistic effect on the arecoline-induced cytotoxicity and glutathione depletion. Other factors associated with malignant transformation of OSMF have been identified. Oesophageal involvement is the most common extraoral manifestation in betel nut chewers. Oesophageal abnormalities were seen more frequently in patients who had consumed a combination of areca nut and tobacco; the oesophagus may also be involved in about twothirds of patients. ${ }^{(2)}$

Table 1: Factors associated with malignant transformation of oral submucous fibrosis.

\begin{tabular}{|c|c|c|c|}
\hline Molecules & Description & Findings & References \\
\hline $\begin{array}{l}0(6)- \\
\text { methylguanine- } \\
\text { DNA }\end{array}$ & $\begin{array}{l}\text { Methyltransferase DNA } \\
\text { repair enzyme }\end{array}$ & $\begin{array}{l}\text { Low levels associated with advanced oral SCC and lymph node } \\
\text { involvement }\end{array}$ & 23 \\
\hline Mutations of $\mathrm{p} 53$ & Tumor suppressor gene & $\begin{array}{l}\text { Degree of p53 staining increased with morphologic } \\
\text { transformation of epithelial cells, associated with progression } \\
\text { of oral SCC }\end{array}$ & 24 \\
\hline $\begin{array}{l}\text { p16INK4alpha/p19 } \\
\text { ARF mutations }\end{array}$ & $\begin{array}{l}\text { p16 regulated } \mathrm{G} 1 \\
\text { proliferation }\end{array}$ & p53 independent pathway of tumorigenesis & 25 \\
\hline $\begin{array}{l}\text { MDM2-P2 } \\
\text { promoter }\end{array}$ & $\begin{array}{l}\text { Transcriptional target of } \\
\text { p53 }\end{array}$ & $\begin{array}{l}\text { Elevated levels of MDM2 protein in dysplastic lesions and oral } \\
\text { SCCs }\end{array}$ & 26 \\
\hline C-jun & Protooncogene & $\begin{array}{l}\text { Chronic stimulation by areca nut and arecoline leading to oral } \\
\text { SSC }\end{array}$ & 27 \\
\hline mtDNA mutations & Mitochondrial DNA & Contributor to the early phase of oral carcinogenesis & 28 \\
\hline HSP70 & Heat shock protein & $\begin{array}{l}\text { Significant correlation of HSP70 expression with consumption } \\
\text { of betel and tobacco; in patients with premalignant lesions } \\
\text { median transition time (premalignancy to malignancy) was } \\
\text { significantly shorter in HSP70 overexpressing cases; oral } \\
\text { cancer patients with elevated levels of HSP70 showed } \\
\text { decreased median disease-free survival time }\end{array}$ & 29 \\
\hline HSP27 & Heat shock protein & $\begin{array}{l}\text { Increased in betel nut-induced oral SCC due to direct action of } \\
\text { arecoline }\end{array}$ & 30 \\
\hline
\end{tabular}




\section{PREVENTION AND TREATMENT}

Patients with OSMF characteristically complain of two problems: an inability to open the mouth, which impedes function, and a burning sensation and intolerance to spicy foods (intolerance to normal diet in severe cases). Management aims to reverse or alleviate these signs and symptoms, stop the disease progressing, and minimise the risk of malignant transformation. The current protocol for the management of OSMF can be divided into 3 broad groups: surgical, physical, and medical treatments.

(1) Surgical treatment: used mainly to manage trismus, involves incising and releasing the fibrotic areas, and leads to further scarring and fibrosis. The introduction of remote tissue (pedicled, such as a buccal fat pad, nasolabial or platysmal flaps, or free tissue transfer) in an attempt to release fibrosis is one approach but results are variable.

(2) Physical treatment: attempts to influence the remodelling of tissue by using movement - for example, exercises and physiotherapy, various splints or other devices to improve mouth opening, or localised heat (such as with microwave diathermy.

(3) Medical treatment: includes dietary supplements (vitamins, antioxidants), the use of anti-inflammatory drugs (principally corticosteroids), proteolytic agents (such as hyaluronidase), anticytokines, and other agents that are not available in the UK. They can be given orally, topically, or by submucosal injection. Operation is generally reserved for established cases of OSMF while physical treatment is usually combined with all other interventions.

\section{CONCLUSION}

As management of OSMF aims to slow the progression of the disease and adding different endeavours to control OSMF and better legislation to govern the availability and sale of areca-nut is recommended so that such type of problem can be handled easily. As such type of disease is controlled by composite work of doctor and patient to cure such type of disease.

\section{Source(s) of support or funding: None Conflicting Interest: Nil}

\section{ACKNOWLEDGEMENT- None}

\section{REFERENCES}

1. Arakeria G, Brennan PA. Oral submucous fibrosis: an overview of the aetiology, pathogenesis, classification, and principles of management. Br J Oral Maxillofac Surg 2013; 51: 587-593

2. Wollina U, Verma SB, Ali FM, Patil K. Oral submucous fibrosis: an update. Clinical, Cosmetic and Investigational Dermatology 2015:8

3. Pindborg JJ, Sirsat SM. Oral submucous fibrosis. Oral Surg Oral Med Oral Pathol 1966; 22:764-79

4. Selvam np, Dayanand AA. Lycopene in the management of oral submucous fibrosis. Asian J Pharm Clin Res, 2013; 6: 58-61

5. Angadi PV, Rao SS. Areca nut in pathogenesis of oral submucous fibrosis:revisited. Oral Maxillofac Surg 2011; 15:1-9

6. Pindborg JJ, Mehta FS, Gupta PC, Daftary DK. Prevalence of oral sub mucous fibrosis among 50915 Indian villagers. $\mathrm{Br}$ J Cancer 1968; 22: 646-54.

7. Khanna SS, Karjodkar FR. Circulating Immune Complexes and trace elements (Copper, Iron and Selenium) as markers in oral precancer and cancer: a randomised, controlled clinical trial. Head Face Med 2006; 2:33.

8. Sirsat SM, Pindborg JJ. Subepithelial changes in oral submucous fibrosis. Acta Path Microbial Scand 1967; 70:161-173.

9. Samdariya S, Kumar D, Kumar A, Porwal P, Pareek P. Oral submucous fibrosis - A 
short review. Int $\mathrm{J}$ Med Sci Public Health 2014; 3:1308-1312.

10. Angadi PV, Rao SS. Areca nut in pathogenesis of oral submucous fibrosis:revisited. Oral Maxillofac Surg 2011; 15:1-9.

11. Pillai R, Balaram P. Pathogenesis of oral submucous fibrosis: relationship to risk factors associated with cancer. Cancer 1992; 69:2011-20.

12. ChaudharyAK, Singh M, Singh M, Mehrotra R. Correlation of histopathological diagnosis with habits and clinical findings in oral submucous fibrosis. Head \& Neck Oncology 2009; 110

13. Sinor PN, Gupta PC, Murti PR, et al. A case control study of oral sub-mucous fibrosis with special reference to the etiologic role of areca nut.J Oral Pathol Med 1990; 19:94-8

14. Tilakaratne WM, Klinikowski MF, Saku T, Peters TJ, WarnakulasuriyaS. Oral submucous fibrosis: review on aetiology and pathogenesis. OralOncol 2006; 42:561-8.26

15. Jacob BJ, Straif K, Thomas G, et al. Betel quid without tobacco as a risk factor for oral precancers. Oral Oncol. 2004; 40(7):697-704.

16. Jeng JH, Tsai CL, Hahn LJ, Yang PJ, Kuo YS, Kuo MY. Arecoline cytotoxicity on human oral mucosal fibroblasts related to cellular thiol and esterase activities. Food Chem Toxicol. 1999; 37(7):751-756.

17. Kaur J, Rao M, Chakravarti N, et al. Coexpression of colligin and collagen in oral submucous fibrosis: plausible role in pathogenesis. Oral Oncol. 2001; 37(3):282-287.

18. Pandiar D, Shameena P. Immunohistochemical expression of CD34 and basic fibroblast growth factor (bFGF) in oral submucous fibrosis. $\mathrm{J}$ Oral Maxillofac Pathol. 2014; 18(2):155-161.
19. Tsai CH, Lee SS, Chang YC. Hypoxic regulation of plasminogen activator inhibitor-1 expression in human buccal mucosa fibroblasts stimulated with arecoline. J Oral Pathol Med. Epub November 4, 2014

20. Avinash Tejasvi ML, Bangi BB, Geetha P, et al. Estimation of serum superoxide dismutase and serum malondialdehyde in oral submucous fibrosis: a clinical and biochemical study. J Cancer Res Ther. 2014; 10(3):722-725.

21. Hu Y, Jian X, Peng J, Jiang X, Li N, Zhou S. Gene expression profiling of oral submucous fibrosis using oligonucleotide microarray. Oncol Rep. 2008; 20(2):287294.

22. Khan I, Kumar N, Pant I, Narra S, Kondaiah P. Activation of TGF- $\beta$ pathway by areca nut constituents: a possible cause of oral submucous fibrosis. PLoS One. 2012; 7(12)

23. Chang YC, Hu CC, Tseng TH, Tai KW, Lii CK, Chou MY. Synergistic effects of nicotine on arecoline-induced cytotoxicity in human buccal mucosal fibroblasts. J Oral Pathol Med. 2001; 30(8):458-464.

24. Baral R, Patnaik S, Das BR. Cooverexpression of $\mathrm{p} 53$ and c-myc proteins linked with advanced stages of betel- and tobacco-related oral squamous cell carcinomas from eastern India. Eur J Oral Sci. 1998; 106(5):907-913

25. Hsieh LL, Wang PF, Chen IH, et al. Characteristics of mutations in the p53 gene in oral squamous cell carcinoma associated with betel quid chewing and cigarette smoking in Taiwanese. Carcinogenesis. 2001; 22(9):1497-1503.

26. Lee HC, Yin $\mathrm{PH}, \mathrm{Yu} \mathrm{TN}$, et al. Accumulation of mitochondrial DNA deletions in human oral tissues - effects of betel quid chewing and oral cancer. Mutat Res. 2001; 493(1-2):67-74. 
27. Kaur J, Srivastava A, Ralhan R. Expression of $70-\mathrm{kDa}$ heat shock protein in oral lesions: marker of biological stress or pathogenicity. Oral Oncol. 1998; 34(6):496-501.

28. Rajendra R, George B, Sivakaran S, Narendranathan N. Visceral organ involvement is infrequent in oral submucous fibrosis (OSF). Indian J Dent Res. 2001; 12(1):7-20.

29. Lee SS, Tsai CH, Ho YC, Yu CC, Chang YC. Heat shock protein 27 expression in areca quid chewing-associated oral squamous cell carcinomas. Oral Dis. 2012; 18(7):713-719.

30. Tung CL, Lin ST, Chou HC, et al. Proteomics-based identification of plasma biomarkers in oral squamous cell carcinoma. J Pharm Biomed Anal. 2013; 75:7-17. 